\title{
Pointless diversity training: unconscious bias, new racism and agency
}

Mike Noon (Queen Mary University of London)

Accepted on June 7th 2017 for publication in Work, Employment \& Society.

\section{$\underline{\text { Abstract }}$}

The latest fashion of 'unconscious bias training' is a diversity intervention based on unproven suppositions and is unlikely to help eliminate racism in the workplace. Knowing about bias does not automatically result in changes in behaviour by managers and employees. Even if 'unconscious bias training' has the theoretical potential to change behaviour, it will depend on the type of racism: symbolic/modern/colour-blind, aversive or blatant. In addition, even if those deemed racist are motivated to change behaviour, structural constraints can militate against pro-diversity actions. Agency is overstated by psychology-inspired, 'unconscious bias training' proponents, leading them to assume the desirability and effectiveness of this type of diversity training intervention, but from a critical diversity perspective (sociologically influenced) the training looks pointless.

\section{Key words}

discrimination, diversity training, equal opportunities, racism, unconscious bias

\section{$\underline{\text { Introduction }}$}

The latest fashion in diversity management is 'unconscious bias training' whereby managers and employees are first put through on-line tests that almost invariably prove they are all biased and are then required to discuss how they can manage this bias to prevent it having a negative effect on workplace social interactions and decisions. The importance of recognising and tackling unconscious bias has been given impetus by the UK government's announcement of name-blind CVs for civil service recruits and similar initiatives by high profile graduate recruiters such as Deloitte, KPMG, HSBC, BBC, and the NHS. The professional body, the Chartered Institute for Personnel and Development, has called for this to be extended to age, and some organisations have blinded other aspects, for example, the law firm Clifford Chance have been obscuring details of applicants' universities to try to eliminate the Oxbridge bias of their recruiters. Facebook is perhaps the best known organisation to declare its commitment to tackling unconscious bias and has published its training material on line (https://managingbias.fb.com) for other organisations to share. More 
recently, a government sponsored report has recommended the creation of a free, online unconscious bias training resource available to everyone in the UK and mandatory unconscious bias training for all employees in all organisations, with additional intensive sessions for managers and executives (McGregor-Smith, 2017).

While the intention of addressing bias is laudable, the awareness training that typically accompanies these initiatives makes a series of assumptions about bias and pro-diversity action that can be challenged from a critical diversity perspective. This article argues that by incorporating sociological reasoning into what has been principally a psychology-led diversity initiative, there can be a more robust evaluation of unconscious bias in general, and racial bias in particular. The argument developed below is split into two components: first, to relate bias to types of racism; and second to moderate the over-emphasis on agency. Both components raise concerns about the supposed value and potential effectiveness of 'unconscious bias training'.

\section{$\underline{\text { Unconscious bias and racism }^{1}}$}

Typing the term 'unconscious bias' into a search engine produces plenty of hits and many definitions. The following features sum up the general standpoint:

Everyone possess bias

People are mostly unaware of the bias

It is deeply engrained

It influences attitudes

It probably influences behaviour

It can be measured (or at least quantified)

Ubiquity and quantifiability are the features most likely to explain why the concept is popular in the diversity management realm. Social psychologists have developed various methods of accessing the biases people possess, but most influential have been the computer based Implicit Association Tests, among which the Harvard IAT (Greenwald et al. 1998) stands out as widely used and extensively cited. These types of tests evaluate a person's positive and negative associations between concepts, images or words, and are deployed by social scientists for a range of purposes (from evaluating voting intentions to exploring patterns of consumption). In particular they are used to evaluate forms of bias - such as racial preference - that might be 'unconscious', that is, not 
explicitly acknowledged by the individual being tested. The IAT is based on the principle that the time it takes to respond to a particular stimulus (the response latency, measured in micro-seconds) is an indicator of the strength of an association. For example, in relation to the IAT designed to measure racial bias, then participants see images of people from different ethnic backgrounds and pair them with a range of positive and negative attributes. For each participant the tests are repeated in various formats and at the end of the battery the participant is provided with a score of his or her racial preference for one group over another. The benefits of using the IAT is that, unlike self-report measures, the participant cannot easily manipulate the response, and the bias can be evaluated even if the participants are unaware of their bias or claim not to hold strong views or opinions.

The use of the IAT is not without critics; for example, Blanton and Jaccard (2008) provide a meticulous dissection of the measurement methods and scientific robustness of the Harvard IAT designed to measure racial bias, leading them to call for caution and dismiss the claims of pervasive unconscious racism as not yet empirically proven (see also Fiedler et al, 2006). The argument developed in this article is less concerned with the integrity of the measure than its potential influence in defining and direct diversity management interventions. So the science behind the test and the quality of the work of the psychologists is not being questioned here, but concerns are being raised about the absence of adequate reflection on the social implications and conceptual underpinning in transposing tests of bias into diversity interventions intended (laudably) to address racial disadvantage. ${ }^{2}$

The unconscious bias narrative generally takes the form of an assertion that almost everyone is a suppressed racist (or at least exhibits a strong racial preference). The evidence for the generalisation about racism comes from the Harvard race IAT: 78 percent show implicit bias on the IAT, with 85 percent of Whites biased against Blacks (Greenwald and Krieger, 2006). The narrative then asserts that since this acts at an unconscious level it influences our decisions and actions, but knowing about preferences brings them to the surface and allows people to take action to moderate them, hence the need for unconscious bias training.

There is a huge leap from knowing about bias to acting differently that is assumed by proponents of unconscious bias training initiatives ${ }^{3}$. Here is where a critical diversity perspective (sociologically influenced) can be deployed: first, to examine the varieties of racism that underpin bias and the likely effectiveness of 'unconscious bias training' (henceforth UBT) in influencing racists; and second, to critique the overstatement of agency and the assumed pro-diversity direction of changed behaviour. 


\section{Racial bias and theories of new racism}

A contemporary line of reasoning is that traditional, blatant racism has been suppressed and that expressions of racism take more subtle, covert and less visible forms. These forms of 'new racism' (Barker, 1981; Sniderman et al. 1991) are a result of changing social norms that render it no longer acceptable openly to express racist views, and reinforced by laws restricting particular behaviours and practices within workplaces. Two theory groups define they key elements of new racism and offer different but largely complementary emphases to explain the changes in the contemporary expression of racism.

\section{New racism 1: Symbolic racism/modern racism/color-blind racism}

There are some subtle differences between the conceptualisation of symbolic racism (Sears and Henry, 2003; Sears 1988), modern racism (McConahay, 1986) and colour-blind racism (BonillaSilva, 2002) but they can be clustered together here due to their common themes. Theorists suggest that animosity towards racial minorities remains deeply embedded but is less likely to be expressed through blatant prejudice than through actions that fail to help or to support the advancement of minorities, such as criticism of, or non-compliance with, workplace equality/diversity initiatives. Similarly, this is coupled with an opinion that racial discrimination is no longer a problem and that ethnic minorities are pushing too far and too hard. Importantly, these views are associated with conservative values that are resistant to changes that might undermine certain core beliefs, particularly individualism and self-reliance. Finally, they also share a common assumption - but most clearly expressed in modern racism - that the values are deeply embedded because they are learned in childhood, reinforced through peer groups and perpetuated through stereotypes in the media. The negative racial attitudes are not acquired through personal experience of inter-racial encounters.

The preferences and attitudes are explicit rather than hidden. Symbolic, modern and colourblind racists are aware of their biases and do not conceal their views since they are expressing a socially acceptable form of racism. Indeed, it might be argued that there is nothing particularly new about these forms, merely they are a moderated expression of racial bias reflecting the changing social context and more tolerant social norms - although exponents of the theories have demonstrated empirical differences from traditional racism, for example Sears et al., 1997. Whether a distinctive step or simply a continuation, it is likely that UBT would have no impact on symbolic, modern or colour-blind racists because they would be unsurprised and unperturbed by their IAT 
result (since they are self-aware in relation to their race attitudes, Nail et al. 2003) and therefore would not need this result to stimulate reflection on how their racial preferences might inform and guide their behaviours.

New racism 2: Aversive racism

The theory of aversive racism (Gaertner and Dovidio, 1986; Dovidio and Gaertner, 2000) proposes that some people are proud about their lack of prejudice and they express egalitarian views, yet deep-down they hold negative beliefs about racial minorities due to discomfort or anxiety stemming from their own sociocultural influences. As a consequence, their actions and behaviour manifest a subtle racism that becomes evident where there are ambiguous social norms, where discrimination against a particular ethnic group can be rationalised by reasons other than race (for example, business needs) or where there is opportunity for prosocial behaviour to their own group (for example, discounting negative aspects of same group candidates when making selection decisions, Dovidio and Gaertner, 2000).

Given that aversive racists are unaware of their condition, the IAT might seem a valuable tool in accessing their unconscious biases. Indeed the technique has been used to distinguish aversive racists from truly non-prejudiced people: both hold low-prejudiced explicit attitudes, but aversive racists have high prejudiced implicit attitudes (Son Hing et al., 2008). This lack of awareness of their prejudices renders aversive racists immune to standard methods of race awareness training where the immorality, illegality or business penalty of prejudice is stressed: immune not because they do not accept these issues as important but because aversive racists think the issues do not apply to them, given they credit themselves with being both non-prejudiced and advocates of egalitarian values. Logically, it might also be assumed that UBT is an alternative intervention ideally suited to aversive racists since it reveals something they do not know about themselves and confronts them with the unpalatable message that they have deep set race-biases, in spite of their claims to be non-racist in their talk and action. The problem with this revelation is that it does not necessarily lead to a change in action. Researchers have found that one consequence for some aversive racists armed with this greater self-awareness is that they become worried about their behaviour and withdraw from encounters with other racial groups for fear that they will say or do something offensive (Gaertner and Dovidio, 1986). Moreover, becoming aware of bias and being told to act differently does not change the residual unconscious bias. 
To sum up, only the aversive racists are likely to be amenable to UBT, and even then it is unclear whether exposure to self-reflection will lead to behavioural change. The other types are likely to be unchallenged and unmoved by learning of their biases, and are unlikely to change their behaviour. Ironically, those most likely to be amenable to UBT are not found among the racist types above but are those who are displaying the lowest (or no) racial preference and who may be already committed to enacting equal opportunity principles. Of course, they are also the people who least need UBT.

\section{The unconsciousness of bias and the issue of agency}

The failure to recognise that UBT is likely to be least effective for those whose actions most need modification is due to the inadequate treatment of agency and responsibility. Part of the allure of the notion of unconscious bias is that it is not about blame. It is convenient to believe that racial discrimination is not a product of our conscious thought but deeply embedded, so discrimination is not really our fault. It is the expression of something unspecified and possibly primeval such as fear of outsiders, threat to the group, or need for group membership and protection. This admonishes the symbolic racist of responsibility for their own racially discriminatory action while reaffirming their right to assert their cultural (and conservative) values. It provides a convenient excuse for continuing to say and do the same things. For the aversive racist, once they have recovered from the shock of finding out they are really a racist deep down, they might change, but equally they might decide this is beyond their control and not alter their behaviour.

The no-blame view that people are ignorant about the pervasiveness of their racial preferences leads to a possible explanation of 'false consciousness' (along with its conceptual limitations). The argument might run as follows. Unaware of their true biases, the manager or employee cannot fully recognise the reality of their attitudinal frame of reference, so cannot therefore choose to act in the best interests of equality and diversity; however the objectivity of the IAT reveals a truth about racial preference which, although sometimes unpalatable, allows the individual to choose his or her present and future action from an informed perspective. Of course, this explanation is replete with problems: the supposed lack of individual self-awareness; the assumption that others objectively know best; the implication that agency can only be enacted in the light of objective revelation; and the underlying validity of the test and artefacts of measurement. 
Even if agency is assumed to be potentially enacted through awareness of bias, then studies have not proven a direct causal link between IAT score and discriminatory behaviour (for insight into the debate among psychologists, see Tetlock and Mitchell, 2009 and Josta et al., 2009). An obvious explanation is that people self-regulate their behaviour, so do not operate solely on the deep-set biases, but are guided by social norms and constrained by opportunities and organisational rules (both formal and informal). Moreover, even if unconscious bias is a problem because of the impact on behaviour in some circumstances, there is the distinct possibility that UBT is not the solution. In a systematic evaluation of diversity programmes for the advancement of women and ethnic minorities into management, Kalev et al. (2006) found diversity training initiatives addressing bias to be one of the least effective methods. Indeed, such interventions have been found in some circumstances to solidify existing attitudes or create backlash (Kulik et al. 2000; Kowal et al. 2013). From an extensive review of 985 published studies of prejudice reduction, Paluck and Green (2009) conclude that there are plenty of ideas and theories, but no evidence conclusive enough to develop confident policy making. More recently, a meta-analysis of the effects of diversity training (covering 260 studies published over the last 40 years) leads the authors to argue that while there is evidence of diversity training success in the short term and especially when combined with other initiatives, there is 'no compelling evidence that long-term effects of diversity training are sustainable in relation to attitudinal/affective outcomes' (Bezrukova et al, 2016: p1243).

Notwithstanding the criticism so far, let us assume that awareness of bias by individuals can lead to a change in their actions, or at the very least can have a consciousness-raising effect that might start the process of change. There remains a huge question about the willingness of the individual to change. It has already been noted above that it will depend on the type of racism, but overlaying this are issues of context and praxis. Social psychologists have shown that in experimental conditions behavioural changes can occur when individuals are exposed to their prejudices and stereotypes, but self-regulation is most likely when there are low time pressures, the need for accuracy is very high, and the outcome is important and depends on high levels of cooperation (e.g., Brief and Barsky, 2000; Devine, 1989; Fiske, 2002; Monteith, 1993). In the normal, day-to-day operations of organisations, such conditions are rare. From a comprehensive review of the evidence, Quillan (2006: 319) concludes that 'implicit biases are more strongly linked to subtle behaviours that are difficult to control, such as nonverbal behaviour in interaction, whereas explicit biases are more strongly related to verbal statements.' In other words, even if an individual is motivated to act, the actual effect on a wide range of his or her behaviour is likely to be limited. 
From a sociological perspective the limited proven effectiveness in changing behaviour presents a huge deficiency because research reveals that racial discrimination is covertly and perniciously secreted in the small, commonplace actions and interactions of workplace. These are not new phenomena but become more visible when acts of overt racism recede. Conceptualised variously as everyday racism (Essed, 1991), subtle discrimination (Rowe, 1990), micro-aggressions (Sue et al, 2007) and selective incivility (Cortina, 2008), the common root is both their focus on the ordinary events of working life, and their reliance on the accounts of social action by those who experience them: the targets of discrimination. Van Laer and Janssens (2011), Deitch et al. (2003) and Ogbonna and Harris (2006) identify and categorise acts with the defining features of being small with attributional ambiguity. For example, compared with others, a person's opinion seems to be ignored more frequently, they do not seem to be praised for good work, they get challenging comments about their religion or background, the lift door is not held for them, or they have their authority questioned. For each of these micro acts the person cannot be certain that perpetrators have a racial motivation behind their action. With no prima facie evidence, organisational equality and diversity policy, grievance procedures or discrimination law can offer no support.

Collectively, this type of behaviour has the powerful effect of signalling to organisational participants that they do not really belong - highlighted vividly by the 'I too am Harvard' campaign". These behaviours can constitute the informal workplace culture and can influence the processes through which people become included in or excluded from organisational life. In addition, persistent and pernicious everyday discrimination can have a detrimental effect on the well-being of the targets, not least because of the stress caused by the attributional ambiguity and the absence of means of redress (see Deitch et al 2003 for a discussion of evidence). If UBT cannot influence these everyday acts then the lived experiences of ethnic minorities are not altered, so what is the point of the training?

What of structure in all this? The focus on individual preferences produces profiles of bias that imply potential for discriminatory treatment, action or decisions. The emphasis therefore lies with changing the behaviour of individuals rather than exploring the structures and context that might produce and reproduce bias. In many respects the forward-looking approach - with the message that what matters is the action you take in the future - fits with a blame-free and optimistic narrative that assumes changes in individual behaviour will eliminate discriminatory treatment. This wholly agent-focused approach understates or ignores the structural constraints of action. Structures are hugely important in embedding racial disadvantage, sometimes labelled institutional racism, and making organisations resistant to agendas for change. This has been well documented 
empirically in WES (recent examples include Harris and Ogbonna, 2015; Hudson et al. 2017; McGinnity et al. 2011). Solutions can range from advocating liberal, incremental initiatives associated with positive action (for example, Ashley 2011) to calls for the radical intervention of positive discrimination (for example, Noon 2010). Studies falling within this range do not deny the role of agency - indeed they invariably identify management choice in the decision processes - but they underline the importance of organisational processes, habitus and power resources. The persistent of disadvantage suggests that a turn towards the individual is the wrong direction. Instead there is the potential need to seek interventions that address social group disadvantage by focusing on fair distribution in the outcomes of social rewards. This might require (as argued by Noon, 2010) a reconsideration of positive discrimination (even if selective and temporary) or less extreme progressive interventions such as matched shortlists or tie-break decisions where social group characteristics are taken into account (allowable under the UK's 2010 Equality Act).

While the turn towards the racist individual potentially distracts from the long-standing issues of structural disadvantage and overstates the agency of organisational members, it is consistent with the general drift towards the individualisation of the equality agenda with the emergence of managing diversity. Just as the diversity agenda has superseded the equality agenda, so the individual has replaced the collective as the object of analysis and intervention, thus failure can be attributed to individual action rather than collective responsibility. Denuded further, the agency of the individual is sourced to a deep-set, unconscious bias and responsibility is pushed further away from the systemic failures of the processes, procedures and operations of the organisation. Ironically and optimistically, the ultimate reduction to the unconscious mind can reopen sociological explorations of structural constraint (such as education, upbringing, socialisation and context) if explanations and remedies are sought for the origins and pathology of bias. My advocacy is for work sociologists and critical organisational theory scholars to take this opportunity to engage with, deepen and diversify the narrative of unconscious bias. For example, it might be possible to deploy Brook's (2013) interpretation of the dialogical self which allows exploration of the tension within the individual in work and through the collective experience of work; this locates social context, power, subjectivity and agency. Equally, for example, the articulation of emotionologies by Fineman (2008) might be of relevance to explore the way dominant social values are reproduced (discursively and through institutional practices) and influence a range of feelings, including attitudes towards others. These subtle and (arguably) unconscious influences derive from social context and can only be challenged through social action. It requires looking within and beyond the individual. 


\section{Conclusion}

This article is encouraging critical debate about the value and use of the technique of unconscious bias training that is currently fashionable in organisations, often led by diversity consultants and greatly influenced by psychology. At present, the UBT initiatives are in their infancy and the flurry of interest must be due to their intuitive appeal to managers because there is no evidence base of effectiveness. This is particularly concerning given there are already a wide range of longer-standing diversity training interventions that seek to educate, influence attitudes and impact behaviour, offering different pedagogical approaches and content (Swan 2009) and which create important, safe, reflexive conditions for participants to explore group dynamics. The purpose of the critique above is not to disparage attempts to reduce bias but to question whether this latest particular fashion for UBT is likely to be any more robust. The conceptual scrutiny above in relation to racial bias suggests not and the following question emerges. What is the point of UBT if the measurement technique shows everyone is biased, there is no proven link between knowing about bias and changing behaviour, only one sub-group (aversive racists) are likely to self-reflect enough to perhaps change their behaviour, and the type of change will likely have least impact on the most pernicious everyday racism in the workplace?

Beyond the conceptual concerns, there is also the need to address a series of empirical questions such as: what are varying forms and types of UBT tools and techniques? What are the effects of these interventions? How do they differ in comparison? What kinds of organisations are adopting UBT, for which groups and for what reasons? What is the role of diversity consultants as agents in the process of UBT adoption? Finally, there are also the questions of why UBT should be more effective than other diversity training initiatives (which have a patchy record), and whether there are particular contexts or circumstances that might influence success or failure of UBT initiatives.

The critique presented above does not challenge the laudable motive of removing the consequences of racial bias, but questions whether UBT is the appropriate solution for this particular problem. One danger is that UBT is adopted as a quick-fix rather than the start of an on-going and possibly lengthy process of reflection, discussion and awareness-raising, in keeping with cooperative learning approaches. By adopting UBT, senior managers can demonstrate that their organisation is taking action to tackle the problem of racial bias, which can also be legitimised as scientific (to help convince the sceptics), but it has the traits of a fad suited to a resurgence in behavioural science in an era of big data. This is not necessarily bad if it gets people talking about discrimination, but it is yet another distraction from the embedded, structural disadvantages within organisations; 
disadvantages that require far more radical solutions than introspective sessions that simply nudge managers and employees, often begrudgingly, into recognising that they are biased.

\section{$\underline{\text { References }}$}

Ashley L (2010) Making a difference? The use (and abuse) of diversity management at the UK's elite law firms. Work, Employment and Society 24(4): 711-727.

Barker M (1981) The New Racism: Conservatives and the Ideology of the Tribe. London: Junction Books.

Bezrukova K, Spell CS, Perry JL, Jehn KA (2016) A meta-analytical integration of over 40 years of research on diversity training evaluation, Psychological Bulletin 142(11): 1227-1274.

Blanton H, Jaccard J (2008) Unconscious racism: a concept in pursuit of a measure. Annual Review of Sociology 34: 277-297.

Bonilla-Silva E (2002) The linguistics of color-blind racism: how to talk nasty about blacks without sounding "racist". Critical Sociology 28(1-2): 41-64.

Brief AP, Barsky A (2000) Establishing a climate for diversity: the inhibition of prejudiced reactions in the workplace. Research in Personnel and Human Resources Management 19: 91-129.

Brook P (2013), Emotional labour and the living personality at work: labour power, materialist subjectivity and the dialogical self. Culture and Organization 19(4): 332-352.

Cortina LM (2008) Unseen injustice: incivility as modern discrimination in organizations. Academy of Management Review 33(1): 55-75.

Deitch EA, Barsky A, Butz RM, Chan S, Brief AP and Bradley JC (2003) Subtle yet significant: the existence and impact of everyday racial discrimination in the workplace. Human Relations 56(11): 1299-1324.

Devine P G (1989) Stereotypes and prejudice: the automatic and controlled components. Journal of Personality and Social Psychology 56(1): 5-18.

Dovidio JF, Gaertner SL (2000) Aversive racism and selection decisions. Psychological Science 11(4): 319-323.

Essed P (1991) Understanding Everyday Racism. London: Sage.

Fiedler K, Messne C and Bluemke M (2006) Unresolved problems with the "I", the " $\mathrm{A}$ " and the " $\mathrm{T}$ ": a logical and psychometric critique of the Implicit Association Test (IAT). European Review of Social Psychology 17(1): 74-147.

Fineman, S. (2008) Introducing the emotional organization. In Fineman S (ed) The Emotional Organization. Oxford: Blackwell, 1-14. 
Fiske ST (2002) What we know now about bias and inter group conflict: the problem of the century. Current Directions in Psychological Science 11(4): 123-128.

Gaertner SL, Dovidio JF (1986) The aversive form of racism. In Dovidio JF, Gaertner SL (eds)

Prejudice, Discrimination, and Racism. Orlando, FL: Academic Press, 61-90.

Greenwald AG, Krieger LH (2006) Implicit bias: scientific foundations. California Law Review 94(4): 945-967.

Greenwald AG, McGhee DE and Schwartz JLK (1998) Measuring individual differences in implicit cognition: the implicit association test. Journal of Personality and Social Psychology 74(6): 14641480 .

Harris LC, Ogbonna E (2015) Ethnic gatekeeping on the shopfloor: a study of bases, motives and approaches. Work, Employment and Society 30(1): 59-76.

Josta JT, Rudmanb LA, Blairc IV, Carneyd DR, Dasguptae N, Glaserf J et al. (2009) The existence of implicit bias is beyond reasonable doubt: a refutation of ideological and methodological objections and executive summary of ten studies that no manager should ignore. Research in Organizational Behaviour 29: 39-69.

Kalev A, Dobbin F and Kelly E (2006) Best practices or best guesses? Assessing the efficacy of corporate affirmative action and diversity policies. American Sociological Review 71(4): 589-617.

Kowal E, Franklin $\mathrm{H}$ and Paradies Y (2013) Reflexive antiracism: a novel approach to diversity training. Ethnicities 13(3): 316-337.

Kulik CT, Perry EL and Bourhis AC (2000) Ironic evaluation processes: effects of thought suppression on evaluations of older job applicants. Journal of Organisational Behavior 21(6): 689-711.

McConahay JB (1986) Modern racism, ambivalence, and the modern racism scale. In Dovidio JF, Gaertner SL (eds) Prejudice, Discrimination and Racism. San Diego, CA: Academic Press, 91-125.

McGregor- Smith, R. (2017) Race in the Workplace. London: Luminous.

McGinnity F, Lunn PD (2011) Measuring discrimination facing ethnic minority job applicants: an Irish experiment. Work, Employment and Society 25(4): 693-708.

Monteith M J (1993) Self-regulation of prejudiced responses: implications for progress in prejudice reduction efforts. Journal of Personality and Social Psychology 65(3): 469-485.

Nail P R, Harton HC and Decker BP (2003) Political orientation and modern versus aversive racism: tests of Dovidio and Gaertner's 1998 integrated model. Journal of Personality and Social Psychology 84(4): 754-770.

Hudson M, Netto G, Noon M, Sosenko F, de Lima P and Kamenou-Aigbekaen (2017) Ethnicity and low wage traps: favouritism, homosocial reproduction and economic marginalization. Work, Employment and Society January 12017 DOI: 10.1177/0950017016674898 
Noon M (2010) The shackled runner: time to rethink positive discrimination? Work, Employment and Society 24(4): 728-739.

Ogbonna E, Harris LC (2006) The dynamics of employee relationships in a diverse workforce. Human Relations 59(3): 379-407.

Oswick C, Noon M (2014) Discourses of diversity, equality and inclusion: trenchant formulations or transient fashions? British Journal of Management 25(1): 23-39.

Paluck EL, Green D P (2009) Prejudice reduction: what works? A review and assessment of research and practice. Annual Review of Psychology 60: 339-367.

Quillan L (2006) New approaches to understanding racial prejudice and discrimination, Annual Review of Sociology 32: 299-328.

Rowe MP (1990) 'Barriers to equality: the power of subtle discrimination to maintain unequal opportunity. Employee Responsibilities and Rights Journal 3(2): 153-163.

Sears DO (1988) Symbolic racism. In Katz P, Taylor D (eds) Eliminating Racism: Profiles in Controversy. New York: Plenum Press, 53-84.

Sears DO, van Laar C, Carrillo M, Kosterman R (1997) Is it really racism? The origins of white Americans' opposition to race-targeted policies. Public Opinion Quarterly 61(1): 16-53.

Sears DO, Henry PJ (2003) The origins of symbolic racism. Journal of Personality and Social Psychology 85 (2): 259-275.

Son Hing LS, Chung-Yan GA, Hamilton LK, Zanna MP (2008) A two dimensional model that employs explicit and implicit attitudes to characterize prejudice. Journal of Personality and Social Psychology 94 (6): 971-987.

Sniderman PM, Piazza T, Tetlock PE, Kendrick A (1991) The new racism. American Journal of Political Science 35(2): 423-47.

Sue DW, Capodilupo CM, Torino GC, Bucceri JM, Holder AMB, Nadal, KL et al. (2007) Racial microaggressions in everyday life: implications for clinical practice. American Psychologist 62 (4): 271-286.

Swan E (2009) Putting words in our mouths: diversity training as heteroglossic organisational spaces. In Ozbilgin M (ed.) Equality Diversity and Inclusion at Work. Cheltenham: Edward Elgar, 308-321.

Tetlock PE, Mitchell G (2009) Implicit bias and accountability systems: what must organizations do to prevent discrimination? Research in Organizational Behaviour 29: 3-38.

Van Laer K, Janssens M (2011) Ethnic minority professionals' experiences with subtle discrimination in the workplace. Human Relations 64(9): 1203-1227. 


\section{Endnotes}

1. Racism is used throughout the article to denote an ideological position where race/ethnic categories are deployed to define a racial hierarchy that guides social action. The categories might arise from assumptions about biological determinism or be socially constructed.

2. The long-standing tension between sociological and psychological perspectives plays out in the unconscious bias training approaches, and my argument is that a sociological counter-narrative needs to be developed. The intention is to open up debate, moderate expectations about the assumed need for UBT and caution against possible faddist tendencies to bridge managing diversity and inclusion (Oswick and Noon, 2014).

3. I am grateful to one of the referees for recommending I make clear that unconscious bias training is one of a variety of approaches and there are other longer-standing traditions such as group relations/psychodynamic group work and adult education (for example used by trade unions) that emphasise collective consciousness raising.

4. The 'I too am Harvard' awareness-raising campaign highlighted racial micro-aggressions by showing a series of photos of students holding placards illustrating the types of comments often made to them which ascribed difference, defined them as outsiders and revealed ignorance and prejudice. The campaign was replicated by other universities. 